\title{
LA TEORÍA DEL CONCEPTO EN LA EDAD MEDIA COMO ANTECEDENTE DE LA EDAD MODERNA
}

\author{
Mauricio Beuchot \\ UNAM. Mejico
}

\section{RESUMEN}

En este artículo intento mostrar algunos antecedentes medievales de las teorías del «concepto» que aparecen en la modernidad, p. ej., en Descartes, Berkeley y Kant. Tras una exposición histórica sobre la función cognoscitiva del «concepto» en la filosofía tomista y franciscana, llegamos a la «via moderna» o nominalista, en la que predomina el problema del conocer sobre el del ser. Francisco Suárez abre el camino a la modernidad dando prioridad al aspecto constructivo del conocimiento.

\begin{abstract}
Through this work I pretend to show some medieval backgrounds about theories of «concept» wich have appeared in modernity, e. g., Descartes, Berkeley and Kant. After doing an historical running over cognoscitive function of «concept» in thomism and franciscan philosophy, we get to «via moderna» or nominalism, in wich the matter of Knowing prevails over the question of Being. Francisco Suárez has started out the way towards modernity, giving priority to constructive parts of knowledge.
\end{abstract}

\section{INTRODUCCIÓN}

En esta páginas me propongo mostrar algunos antecedentes medievales de las teorías del concepto que aparecen en la modernidad (p. ej., con Descartes, Berkeley y aun Kant). Éstas fueron gestándose ya desde la escolástica tardía. Ella se presenta como una reacción contra la escolástica anterior y contiene críticas radicales de muchos de los planteamientos de la Edad Media temprana y madura. Esta reacción tardomedieval ha sido vista como una etapa de decadencia y transición. Pero hay, como veremos, pensadores muy conspicuos y críticos, de la talla de cualquiera de los que llevan a sus últimas consecuencias ciertas teorías tardomedievales en la filosofía moderna. En cierta forma se ve un nominalismo predominante que se enfrenta a los diversos tipos de realismo antes reinantes. Y se ve que empieza ya a colocarse como principal el problema del conocer y ya no tanto el del ser. 
Dentro de esa teoría del conocimiento o gnoseología de los escolásticos fue muy relevante el tema del concepto. Este tema venía desde la reflexión aristotélica y, ya sea para defenderlo, ya para rechazarlo, todos los escolásticos hubieron de tomar partido frente a él. Así fue como se tiende una línea que llegará hasta los pensadores de la modernidad, hasta los filósofos modernos. Surgieron, pues, los que defendían el concepto o species y los que Io negaban o disminuían su valor para el conocimiento. La species es la entidad mental por medio de la cual y en la cual se conoce la cosa; así, es una imagen de algo sensible o una idea inteligible, y es lo correspondiente al concepto. Por eso se puede usar species como sinónimo de «concepto» (en el sentido de los modernos). Los que minusvaloraban su función comenzaron proponiendo que, más que el concepto, lo que era objeto de nuestro conocimiento era un ser intencional u objetivo, que no era ni cosa física ni psicológica, sino una entidad distinta, trascendental y subsistente, de tipo cuasi-platónico. Pero, por las críticas, poco a poco los mismo propugnadores de este ser intencional fueron haciéndolo inmanente y poniéndolo en lugar de la species o como la species misma. De esta manera, lo que captan nuestros sentidos no son los accidentes de la cosa real, sino un ser objetivo e intencional que es el esse apparens, esto es, el fenómeno (a saber, no accidentes reales, sino conocidos o fenoménicos); $y$, al nivel intelectivo, no conocemos tampoco las naturalezas o esencias de las cosas reales, sino ese ser objetivo e intencional que nos representa la realidad conocida. Conocemos fenómenos y conceptos (entidades mentales), no objetos o cosas reales. Se da, por tanto, lugar a un fenomenismo como en los empiristas modernos y a un idealismo como el de los racionalistas.

Y, por otra parte, los que niegan el concepto o species, lo hacen para combatir el fenomenismo e idealismo (ya que ven el concepto como entidad vicaria, que entorpecería el acceso al objeto), y para defender el conocimiento intuitivo y directo de la cosa singular, tanto a nivel sensorial como intelectual. Pero con ello borran la especie y la reducen al mero acto de conocimiento, y aun al conocer mismo, $\mathrm{o}$ al conocimiento inmanente que la mente tiene de sí misma. Y de esta manera también se incurre en el idealismo, ya que únicamente es posible conocer la mente, y no el objeto singular, las cosas (o el objeto a través de la mente misma y su acto). Y lo que vemos por cumbre de todo es que ambas corrientes, a saber, tanto la que ataca la species o concepto introduciendo el esse apparens como la que la ataca reduciéndola al solo acto de conocimiento, conducen al escepticismo. En efecto, evitan el realismo, al dejar sólo el conocimiento del objeto pensado, y no del objeto real. Y sólo la corriente que mantiene la species o concepto como algo inmanente al pensamiento, pero como representación fidedigna de la cosa real exterior, pudo mantenerse en la línea del realismo cognoscitivo. Veamos cómo se dio esto.

\section{LA TRADICIÓN ARISTOTÉLICO-TOMISTA}

En el siglo XIII, Sto. Tomás de Aquino (h. 1225-1274) recupera la doctrina de Aristóteles sobre la idea, según la cual, la idea o concepto es un medio y vehículo de 
captación cognoscitiva. Es lo que fue denominado species. ¿Qué es la speciés? La: «r: ic es algo que sucede, que se da en la mente y que metafóricamente puede llamarse «i iceptáculo» o «recipiente» de un contenido cognoscitivo. No es lo que se conoce (id quod), sino por lo que se conoce (id quo). La mente recibe el conocimiento (sensible e inteligible) de la cosa a través de un intermediario que es la especie de la cosa (i.e., su species o semejanza, su representación). ${ }^{1}$ De esta manera, conocer es volverse intencionalmente, esto es, psíquicamente lo conocido, recoger su esencia en una existencia ya no física, sino psíquica, intencional. Esa forma o esencia conocida se recibe en la especie cognoscitiva. Y, ya que el conocimiento es sensible e inteligible, hay tanto especies sensibles como inteligibles. Éstas últimas son las que propiamente reciben el nombre de conceptos.

Centrándonos en este nivel de lo inteligible, veamos qué es para santo Tomás el concepto o especie inteligible. Es, como ya apuntábamos, el receptáculo (medio y representación) de lo conocido por el intelecto. Es el medio por el cual el intelecto obtiene conocimiento de la cosa. Con estos elementos, el realismo se conserva por transitividad: dado que la especie o concepto es la representación más fiel posible de la cosa - ya que es su signo formal y natural, el más perfecto pensable- $-{ }^{2}$ entonces resulta que el conocimiento que mediante ella se recibe es el más fidedigno. El concepto es, por ende, el dispositivo de la mente (intelectiva) para conocer intelectualmente.

El proceso por el que se llega a la especie conceptual es - para Tomás de Aquino-el siguiente. El intelecto era concebido como teniendo una parte activa — constructora- y una parte pasiva — receptora-, aunque ésta última con alguna actividad también (i.e., no es completamente inactiva o estática). Tales partes o aspectos del intelecto eran llamados el intelecto agente y el intelecto posible. El primero despoja a la imagen —o fantasma, como le llamaban los escolásticos - de sus aspectos sensibles e individualizadores, lo «intelectualiza» o abstrae, y lo fija en el intelecto posible; i.e., transforma la imagen (que es una semejanza todavía sensible de la cosa) en una semejanza inteligible, que se llama especie impresa. Y, a su turno, el intelecto posible tiene como «actividad» elaborar esa especie impresa para transformarla en un producto plenamente intelectual, completamente depurado de lo sensible por abstracción, y este producto se llama especie expresa. Ésta última es la que propiamente recibe el nombre de concepto.

1 Sin embargo, no es representacionismo sin más, ya que lo representado es la misma cosa con otra esencia. Es el único signo que retrata la cosa fielmente, es la única representación que es más bien presentación de la cosa. ya que se trata de la misma esencia de la cosa pero con existencia distinta, a saber, en la cosa, la esencia tiene existencia real, en el conocimiento esa esencia pasa a tener existencia mental, psíquica o intencional.

2 El signo formal de los escolásticos es un tipo de signo muy difícil de entender para el hombre moderno. En efecto, se trata de un signo que no sólo es un medio por el cual, sino en el cual, se da lo significado. Además, el único signo formal que hay propiamente es el concepto. Por eso a muchos les parecerá que es un tipo de signo inventado ad hoc, precisamente para que quepan en él los conceptos. Pero no es así; guarda consistencia con toda la teoría semiótica escolástica, en la que hace pareja con el signo instrumental. Y, si no hubiera signo formal junto al instrumental, no sería completa la teoría escolástica del signo. 
El concepto en sí mismo era visto por santo Tomás con dos aspectos, como dos caras de la misma moneda, que recibían los nombres de concepto forma o concepto subjetivo, por una parte, y concepto objetivo o concepto material, por otra. El concepto formal es el mismo concepto en cuanto es una cualidad o modificación de la mente, modificación que tiene que darse para servir de «recipiente» del conociemitno dado; es un accidente de la substancia anímica o mental que funge como receptáculo de un contenido cognoscitivo. Y ese contenido cognoscitivo es justamente lo que se llama concepto objetivo; ya sabemos que dicho contenido cognoscitivo es la propia forma o esencia de la cosa conocida, contenida y representada en la especie o concepto. En el concepto mismo hay, entonces, una parte de continente y otra de contenido: la parte de continente es el concepto como concepto formal y la de contenido es el concepto como concepto objetivo. Así, lo que garantiza la objetividad y el realismo gnoseológico es el concepto objetivo, esa parte o aspecto del concepto que contiene la esencia del objeto conocido; claro que ya no una esencia con existencia física, natural, sino una esencia ahora con existencia psíquica, intencional. Es lo objetivo del conocimiento porque, a pesar de que haya diversidad formal en los conceptos en cuanto al concepto subjetivo, el contenido conceptual es captado por todos de modo idéntico, lo cual se ve en que puede haber una comunicación coherente y fructífera sobre ese conocimiento. Y la parte de diversidad en las maneras de conocer algo sólo puede pertenecer a, o darse en, el concepto formal o subjetivo; pero no afecta a ese contenido cognoscitivo que es como un núcleo de objetividad.

Pues bien, como ya apuntábamos, el concepto o especie es también un signo, una representación de la cosa. Era visto por los tomistas como el signo más perfecto, porque cumplía de la manera más perfecta con la función vicaria del signo, que es llevar al conocimiento de la cosa significada; y este signo que es la species o concepto lleva al conocimiento de su objeto significado en el mismo contenido que presenta, pues ahí va la semejanza perfecta de lo que representa. Y lleva a ella sin distraer o entorpecer ese conocimiento llamando la atención sobre sí mismo en cuanto él mismo es un objeto de conocimiento. Menoscaba su ser de objeto, lo esfuma en favor de su significado, que es la cosa cognoscible y conocida en él y por él. Por ser un signo tan perfecto, era llamado signo formal. Y para la mayoría de los tomistas el concepto era el único que podía ser considerado como tal.

\section{LA LÍNEA FRANCISCANA}

Duns Escoto (h. 1265-1308) rechaza ya el conocimiento por medio de la species. A diferencia de santo Tomás, insiste en el conocimiento intuitivo del intelecto más que en el abstractivo, y en el conocimiento intelectual del singular más que en el del universal. Es decir, no sólo es conocimiento individual el perceptual, sino también el intelectual, a diferencia de lo que decía la tradición aristotélico-tomista: que lo individual pertenecía a los 
sentidos y lo universal al intelecto. Y, finalmente, en el carácter más activo que pasivo del intelecto. Es más intuitivo porque tiene como más propio el conocimiento directo del singular, y de ahí pasa al del universal, por construcción intelectiva. Eso resalta el carácter dinámico del intelecto: es más activo que pasivo. Su actividad consiste en construir el objeto de conocimiento, no en recibirlo simplemente. «Hace» el universal, cognoscitivamente. La abstracción es para Escoto distinta que para santo Tomás; en la abstracción escotista el intelecto agente es activo, pero no en la línea de la universalización, sino como una continuación de la captación intelectiva de lo singular, ya que se reduce a destacar lo que en las mismas cosas singulares hay ya de univeral. Esa presencia de lo universal en los individuos es la natura communis, por las que ya está formalmente en ellas el universal (antes de la intervención del intelecto), y por eso no hay propiamente necesidad de abstracción, sino de construcción interna. Lo universal se capta de modo directo en las cosas, en la misma intuición del singular; con ella se hace a la cosa pasar de su estado natural o físico a un estado intencional o psíquico. Y eso es cambiar la naturaleza de las cosas y construir algo en ella; por eso el intelecto es creativo y activo, y no puramente receptivo y pasivo. $\mathrm{Y}$ el intelecto conoce tanto lo singular como lo univeral en sí mismo, directa e indirectamente, casi sin necesidad de la abstracción, en contra de lo que sostenía santo Tomás. En efecto, Escoto cambió muchísimo la postura de santo Tomás; parece que en las tesis principales se le opone; esto semeja una lucha entre sistemas muy opuestos, como era el predominio del aristotelismo en Tomás y el predominio del platonismo-agustinismo en Escoto. Pero, a pesar de que Escoto está más en el lado platónico que santo Tomás, propiciará en mucho el nominalismo que vino después de él, ya sea por rechazo, ya sea por varias cosas que tomó el nominalismo del escotismo.

Más radical que Escoto se muestra su hermano de hábito Pedro Juan Olivi (1247-1298). Mientras que Escoto no rechazaba el intelecto agente ni la species, él sí rechaza ambas cosas. Considera al conocimiento como algo más simple, como algo que se ejerce de manera más unitaria y directa. Tal se ve en el siguiente texto: «El alma se conoce o se puede conocer de dos maneras. La primera es a modo de conocimiento experimental y casi táctil, Así, sin duda, sabe que es, vive, piensa, quiere, ve, oye y mueve al cuerpo, y sabe de sus demás actos, de los cuales conoce y experimenta que ella es el principio y el sujeto. Y esto en cuanto que no puede actualmente saber o considerar ningún objeto y ningún acto sin que siempre y al mismo tiempo sepa y experimente que ella es el supuesto del acto por el que sabe y considera aquello. Por tanto, en su pensamiento forma siempre la validez de esta proposición: "yo sé y opino de esto, o yo dudo de esto". Pero el alma tiene este conocimiento de por sí por conversión inmediata de su mirada intelectual sobre sí misma y sobre sus actos». ${ }^{3}$ Se le ve con esto como un antecedente del cogito ergo sum de Descartes y del yo pienso o la percepción originaria de Kant. Ya santo Tomás se ve relegado en el enfoque de Olivi, sobre todo por su rechazo de la species, que era tan importante para el Aquinate.

3 P.J. Olivi, Quaest. in II lib. Sent., q. 76, ed. Jansen, Quaracchi, 1942, t. III, 146; cf. E. Bettoni, Le dottrine filosofiche di Pier de Giovanni Olivi, Milán: Vita e Pensiero, 1959. 


\section{LA VIA MODERNA}

Los propios medievales llamaban via moderna a la de los que seguían el espíritu terminista o nominalista, bastante centrado en el problema del conocimiento. De hecho, en el siglo XIV la cuestión de los conceptos fue muy estudiada y debatida, por lo general en contra de los planteamientos anteriores. Surgieron dos corrientes, a la primera de las cuales podemos llamar conceptualismo lógico, que fue predominante entre los dominicos, como Roberto Holcot, Hervé de Nédellec (Herveus Natalis) y Durando de Saint Pourçain, aunque hubo también franciscanos, como Jacques de Esculo, y otros, como Pedro Aureolo y, ya antes, Ricardo de Middletown. La otra corriente puede recibir el nombre de conceptualismo psicológico, y fue predominante entre los franciscanos, en seguimiento de Ockham, pero también se dio en otros, como en Juan de Mirecourt.

El conceptualismo lógico consiste en lo siguiente: introduce —además del acto psíquico de conocimiento y de la species inteligible a la que llama esse subiectivum (y que es también algo psicológico) — un concepto distinto y de tipo platónico, un ser aparte, al que llama esse obiectivum. Podemos compararlo con la postura de Leibniz, Bolzano y Frege: un ser objetivo no real en el sentido de no físico ni psíquico. Algo que, sin pertenecer al intelecto como los otros dos elementos cognoscitivos (i.e., el acto y la especie), pero tampoco al mundo real físico, es la esencia de la cosa conocida con una existencia hipostasiada (así como la species era la esencia de la cosa con una existencia psíquica). Es lo que conoce el intelecto, con lo que se conecta al conocer objetivamente la cosa. Inclusive puede darse la species - como sucede en algunos autores-, pero no es lo que hace conocer (ya que ella es un esse subiectivum), sino que la función propiamente cognoscitiva la tiene el esse obiectivum. Es lo que da objetividad, lo que permanece inmutable a pesar de que los intelectos individuales cambian a cada instante en su misma subjetividad. Esta postura, al relegar la especie como vehículo de conocimiento y poner esa otra entidad, el esse obiectivum, estaba demostrando su desconfianza de que el conocimiento objetivo estuviera en la especie o concepto. Había que ponerlo en otra cosa, en un ser intencional o «ficticio» (como también lo llamaron) fuera de la mente. Era una hipóstasis o cosificación platónica muy extraña en estos pensadores rodeados por un ambiente nominalista. Los actos cognoscitivos y las especies inteligibles se multiplican de acuerdo al número de intelectos; en cambio, el esse obiectivum es transcendente a ellos y al mismo intelecto. Pero, como veremos, el esse obiectivum, intentionale, fictum o apparens condujo a un tipo de fenomenalismo.

A diferencia de este conceptualismo, para el que el concepto es algo trascendente al intelecto, el conceptualismo psicológico rechaza el esse obiectivum y sólo admite los actos cognoscitivos y las especies, y a veces ni las especies, pues las elimina a favor de los actos de conocimiento. ${ }^{+}$

4 Cf. K. Michalski. «Les sources du criticisme et du scepticisme dans la philosophie du XIVe siècle», en el mismo, La philosophie au XIV siècle. Six études, ed. K. Flasch, Fráncfort: Minerva, 1969, p. 47. 
En la línea del conceptualismo lógico, ya el franciscano Ricardo de Middletown (h. 1249-1300/8) distingue entre el concepto psicológico, que es la species, a la que llama universale in repraesentando y el concepto lógico o universale in praedicando. Sólo el segundo es propiamente universal, mientras que el primero es algo singular, un ente individual de la mente. El concepto psicológico o especie existe como algo que es más próximo a la mente que cualquier realidad exterior, mientras que el concepto lógico no existe en el mundo físico, ni como entidad psíquica; sólo es un objeto de conocimiento, una pura representación; como decía este escolástico, es un esse repraesentatum o esse obiectivum. La especie, por lo demás, es en lo que se conoce el ente individual o el universal, y el esse obiectivum es propiamente lo que conocemos: el concepto (lógico) y no la cosa. Pone el esse obiectivum de manera idealista, como lo propiamente conocido, en lugar de la $\cos a^{5}$

El dominico Robeito Holkot (m. 1349), a su vez, dice que el único objeto de la ciencia es la verdad; pero la verdad sólo está contenida en el juicio; por tanto, sólo los juicios (o los conceptos), ${ }^{6}$ y no las cosas, son objeto de la ciencia. Ella es un acto de asentimiento al contenido de un juicio. ${ }^{7}$ El esse intentionale no existe espacio-temporalmente $\mathrm{y}$, sin embargo, se impone a nuestra mente como objeto de conocimiento. Algunos, como Walter de Chatton, vieron con calrividencia que, si se postula el esse obiectivum, no se puede dar ningún juicio verdadero que recaiga sobre una cosa exterior; ${ }^{8}$ y entonces el objeto de nuestro conocimiento no son las cosas, sino los conceptos (lógicos).

Durando de Saint Pourçain (1270/5-1334), dominico, rechaza el intelecto agente. Éste tendría alguna función si existieran los universales como formas separadas, ya que entonces habría que adecuarlas al intelecto y ponerlas como objeto suyo. Pero los universales no son formas platónicas, se reducen a la intentio de la universalidad. Por lo tanto, no se requiere un intelecto agente que conecte al intelecto con ellos. Lo que el dicho intelecto haría sería remover las condiciones individuantes del fantasma o imagen. Sería abstraer. Pero eso no es una acción real; luego sólo puede ser algo de razón. Y no es real porque la actividad del intelecto agente implica una incompatibilidad entre la imagen corpórea y el intelecto incorpóreo. ${ }^{y}$ La idea de intelecto agente tiene una carga de platonismo, lo cual acusa Durando. Lo universal se ve como una forma que pudiera separarse de la imagen. $Y$, al ser inútil el intelecto agente, también el intelecto posible es sólo una pretensión de los mismos teóricos. Pero, como se ha dicho, los universales son inexistentes, son ficciones, y por ende el intelecto agente y el posible son una ficción. Esa distinción del intelecto en agente y en posible no tiene sentido.

5 K. Michalski, «Les courants philosophiques à Oxford et à Paris pendant le XIVe siècle», ibíd., p. 4

6 Los entiende de un modo semejante a Frege, como entidades subsistentes.

7 Cfr. Holkot, In I Sent., q. 3, a. 5, G.

8 Cfr. K Michalski, «Les sources du criticisme», p. 58.

9 Cfr. M.T. Beonio Brocchieri Fumagalli, Durando de S. Porziano. Elementi filosofici della ter zi redazione del "Commento alle Sentenze», Florencia: La Nuova Italia Editrice, 1969, p. 66. 
El concepto o verbum mentis, según Durando, es meramente subjetivo, no le corresponde algo en la realidad objetiva. ${ }^{10}$ Es producto de una acción inmanente del intelecto y, por lo tanto, no puede constituir una relación con un objeto exterior. Eso es concebir la acción del entender a la manera de la acción natural, lo cual es inadmisible. «Por exclusión, Durando concluye que el concepto no es otra cosa que el mismo acto cognoscitivo: por esencia el concepto representa la cosa, y no como signo, como la palabra o la imagen, sino directamente, así que se puede afirmar que el develarse de la cosa al intelecto es exactamente el concepto. En este sentido cualquier acto cognoscitivo, confuso o claro, directo o reflejo, es un concepto, aunque un conocimiento claro e inmediato corresponde más a la definición de concepto como representante». "Además, si el concepto no se resuelve en el entender, el conocimiento sería mediato, pues la forma o species sería la entidad mediadora, y, como entidad tercera entre el intelecto y la cosa, se multiplicaría al infinito. Por otra parte, la species es de la misma naturaleza o esencia que la cosa conocida, sólo que con diferente tipo de existencia; pero, ¿cómo puede ser igual en naturaleza una species, que es accidente de la mente, a una substancia, ya material, ya espiritual, como es la cosa conocida? Todo ello obliga a Durando a aceptar de su hermano de orden, Herveus Natalis, la teoría del concepto lógico o esse obiectivum como objeto del conocimiento: «El universal, la especie y el género no representan nada real, ni en las cosas extramentales ni en el alma misma: son un ser aparte, intencional, en el intelecto, en tanto que son dados al intelecto como objeto de conocimiento». ${ }^{12}$ Este ser intencional y objetivo tiene un carácter de subsistente, más que de existente (como la noción de subsistencia, distinta de la existencia, que sostuviera Bradley, y que tanto criticó Russell, a principios del presente siglo).

Para Pedro Auriol, franciscano (1280?-1322), eso es evidente y así lo asume y lo sostiene. El fenómeno (o esse obiectivum o intentionale) es el objeto inmediato de todo conocimiento. Por ejemplo, los actos de conocimiento sensible versan directamente sobre el esse apparens o intentionale (esto es, el enuntiabile o proposición subsistente) que se da de cualquier objeto por el hecho de ser pensado, ya exista o no. (En ese sentido, sostiene que Dios podría crear en la mente humana representaciones de cosas que no existen. Esto lo atacaron muchos, diciendo que Dios no puede ser engañador y que sostenerlo era una gran blasfemia, pero él daba cabida a esa posibilidad de engaño por parte de él). Lo que dice del conocimiento sensible lo sostiene también para el intelectual. Como argumento aduce que sólo por el esse apparens tienen explicación las ilusiones ópticas, alucinaciones y demás, que no tienen atrás un objeto que actúe sobre los órganos sensoriales. Y, sin embargo, por el solo hecho de pensarlos se produce un ser intencional de ellos en la mente. Todos ellos muestran que los actos de conocimiento versan sobre fenómenos y no sobre cosas reales en sí. Y, como hemos visto en los anteriores filósofos, dicho esse apparens no es real (físico) ni psíquico, sino diferente, pero objetivo, con una existencia transcendental de tipo

10 Cfr. ibid., p. 68.

11 Ibid., p. 72.

12 K. Michalski, «Les courants philosophiques», p. 18. 
platónico. ${ }^{13}$ Y no puede ser algo psíquico porque eso es la species, la cual, sin embargo, se identifica por que el acto de conocimiento, es un id quo, subjetivo, mientras que el esse apparens es un id quod, objetivo. ${ }^{1+}$ Auriol sigue admitiendo el intelecto agente y el posible, pero no les concede poder abstractivo. Mantiene asimismo la species, como esse subiectivum, pero pone al esse obiectivum o apparens como el verdadero objeto de conocimiento. ${ }^{15}$ "Con todo esto tenemos una anticipación de la distinción kantiana entre 'fenómenos' y 'noúmenos'. El entendimiento no percibe las cosas como son en sí mísmas, sino solamente sus 'apariencias' tal como le son representadas en la forma specularis o en el esse intentionale». ${ }^{16}$

Por lo que hace a la corriente conceptualista psicologista, tiene como iniciador y máximo representante al célebre franciscano Guillermo de Ockham (1295/1300-1349/ 1350). Éste se esfuerza por excluir todo intermediario entre el acto de conocimiento - que es intuitivo- y el objeto conocido. Elimina tanto la species como el esse obiectivum. La species queda eliminada por superflua: «Digo que la especie, de cualquier modo que se la llame, nunca debe ser puesta en el intelecto, porque jamás se debe poner la pluralidad si no es necesaria. Pero [...] lo que se puede salvar por tal especie, con la misma facilidad se puede salvar sin ella. Luego no hay que poner tal especie». ${ }^{17}$ Es una aplicación de la famosa navaja de Ockham. Y es que el conocimiento intuitivo se puede realizar sólo con el entendimiento y la cosa, sin necesidad de ninguna species. ${ }^{18}$

Con el mismo conocimiento intuitivo elimina el esse obiectivum. Los sentidos captan inmediatamente los accidentes reales de las cosas y no los fenómenos o presentaciones o apariencias de éstos (el esse apparens de Auréolo). ${ }^{19}$ Todo lo que se interponga entre el objeto y el acto cognoscitivo sería un fictum, algo fingido y falso. El único esse obiectivum que acepta Ockham es el que tiene el ser real cuando está en nuestra mente (la cual es el esse subiectivum ). Da el siguiente argumento: Todo es substancia o accidente; pero el ser ficticio no es ni uno ni otro, luego es contradictorio e inexistente. Además, si se afirma que hay semejanza entre el concepto y su objeto, habría que decir que el concepto es real, pues de otra manera se estaría diciendo que el ser real es representado por nada. Así pues, Ockham rechaza el fenomenismo: los sentidos captan su objeto (la cosa real) de manera inmediata, intuitiva, sin un ente ficticio que funja como mediador. No hay species ni esse apparens o fenómeno intermediario, porque habría que ponerle otro intermediario y así al infinito. Por eso él, quitando todo eso, simplifica y postula la intuición directa en el conocimiento. ${ }^{20} \mathrm{De}$

13 Cfr. K. Michalski, «Le criticisme et le scepticisme dans la philosophie de XIV siècle», loc. cit., p. 123.

14 K. Michalski, «Les courants philosophiques», p. 19 y «Les sources du criticisme», pp. 50-51.

15 Cfr. M. de Wulf, Historia de la filosofía medieval, México: Ed. Jus, 1949, t. 3. p. 26.

16 G. Fraile, Historia de la filosofía, t. II: Edad Media, Madrid, BAC, 1960, p. 1144.

17 Ockham, In I Sent., d. 27, q. 2, K.

18 In II Sent., q. 15, O.

19 Cfr. In I Sent., d. 27, q. 3, I.

20 Cfr. K.Michalski, «Les sources du criticisme», pp. 55 ss. 
esta manera, Ockham rechaza tanto la species como el esse apparens o esse obiectivum y sólo le queda el acto de conocimiento, que es intuitivo. ${ }^{21}$

En esta lucha contra el esse obiectivum como entidad sui generis, Guillermo de Alnwick, franciscano que fue maestro en Oxford hacia 1316, reduce el esse intentionale a la species intelligibilis (o forma repraesentationis). Alnwick argumenta: Todos reconocen el ser real y el ser mental. Los que ponen el esse obiectivum niegan que sea un ser real y un ser mental, y, sin embargo, dicen que es algo positivo, pues subsiste y no está sujeto a la mutación del conocimiento subjetivo. Pero lo que hay son más bien representaciones estables, y su ser positivo es el mismo de las especies inteligibles. Porque el ser positivo es real o mental. Y en este caso el ser que tiene es el de ser algo en la mente, por lo que es un ser mental. Y, si el ser intencional se sigue fatalmente del acto de conocer y de la especie, debe ser de la misma naturaleza que esos antecedentes suyos; pero ellos son entes mentales; luego el ser intencional debe también ser mental, y, por tanto, debe identificarse con la especie. ?2

En esta misma línea, Juan de Mirecourt, cisterciense que fue maestro en Paris en 1344-5, excluye tanto la species como el esse obiectivum. Rechaza la species ya sea que se la entienda de manera aristotélico-tomista, como entidad psíquica mediadora, ya sea que se la entienda de manera ockhamista, como el mismo acto de conocimiento. Simplifica mucho más que Ockham; las ideas no son accidentes distintos de la substancia anímica, sino modos de ser y de reaccionar de la misma alma, sus modos de darse, identificados en realidad con ella. (Ontológicamente, aquí está larvada la tesis — de Nicolás de Autrecourt- de que sólo existen las substancias, sin ninguna clase de accidentes, los cuales serían producto del sujeto cognoscente). ${ }^{23}$ Pero también ataca Mirecourt el esse obiectivum en su forma fenomenista del esse apparens, porque - según dice-conduce a desdoblar el mundo exterior: la piedra tiene un tipo de ser en la mente y otro tipo de ser fuera de ella. Niega todos los eidola o intermediarios entre la cosa y el acto de conocer. Y'repite, como otros, el argumento ockhamista: el esse fictum o esse obiectivum pertenece al ser real o al ser ideal. Si al real, o a la substancia o al accedente. Pero esto lo niegan sus sostenedores. Mas entonces, «se debería admitir un ser ideal que se desliza entre el acto psíquico y el objeto red. Por lo tanto, cada conocimiento sensible tiene como término inmediato el objeto que existe en el mundo exterior y no un fenómeno, un esse apparens. Por lo demás, si el conocimiento del objeto exige como intermediario un fictum, éste exigirá a su turno otro intermediario, y así sucesivamente, sin fin». ${ }^{2+}$

Finalmente, Nicolás de Autrecourt (clérigo secular, h. 1300-1350) -aunque en un fragmento dudoso- dice que admitir que la presencia fenoménica es igual al acto de conocer implica el conocimiento objetivo. Pero con ello la certeza del mundo descansa en

21 Cfr. S. Rábade Romeo, Guillermo de Ockham y la filosofía del siglo XIV, Madrid: CSIC, 1966.

22 Cfr. K. Michalski, «Les sources du criticisme», p. 52.

23 K. Michalski, «Les courant philosonhiques" p. 22.

24. K. Michalski, «I es sources du critị: " me" úv. 
el mismo conocimiento. Por eso la única existencia cierta es la de nuestro conocimiento. Ya que el conocimiento difiere de la cosa conocida, y sólo tenemos acceso al primero, no podemos decir si ésta última existe. Sólo hablamos de fenómenos y no de accidentes reales de las cosas (i.e., sólo hablamos de sensibles o sensibilia, como él los llama). Y por ello no podemos discernir el error en nuestro conocimiento. ${ }^{25}$ Con lo cual sólo queda el escepticismo cognoscitivo.

Vemos, así, en Mirecourt y Autrecourt la eclosión del idealismo o de la consideración de que son las ideas - y no las cosas - las que constituyen el objeto de nuestro conocimiento. Además, en esta misma corriente de conceptualistas psicológicos (adversarios de los conceptualistas lógicos), algunos filósofos ni siquiera consideraban a las ideas o conceptos como entes psíquicos, intermediarios mentalistas del conocer, sino que los reducían a la misma acción cognoscitiva del intelecto, a sus modos de reaccionar o de ser, esto es, a la misma susbstancia de la mente. El conocimiento se ha privado de su aspecto objetivo extramental y todo se conduce al interior del intelecto mismo. No en balde se han visto en autores como Mirecourt y Autrecourt - pero no sólo en ellos- los antecedentes del escepticismo moderno, como, por ejemplo, el humeano.

\section{TRANSICIÓN A LA MODERNIDAD}

La escolástica de los siglos XVI y XVII siguió reflexionando sobre este problema del papel de los conceptos en el conocer. Y el gran propagador de estas reflexiones fue Suárez, debido a la gran difusión que tuvieron sus obras en toda Europa.

Francisco Suárez vuelve a hablar de las species. Pero ya no son el receptáculo del contenido cognoscitivo conceptual, sino el mero «excitante» de la reacción vital del conocimiento. Al igual que para otro jesuita compañero suyo, Gabriel Vázquez, para Suárez la especie es mera imagen del objeto, no ya el objeto mismo con un ser intencional, con una presencia intencional en la mente. La especie no es producto de una recepción, sino producto del intelecto creativo o constructivo; es un constructo. Así, conocer no es ya de suyo captar al objeto mediante una representación de él (representación que sería la species), sino que Suárez quiere recuperar el conocimiento escotista (y ockhamista) intuitivo del singular, y así dice que se conoce directamente - sin que sea necesaria la mediación de la especie - el objeto mismo. En realidad, se suprimen las especies (aunque se las conserva en un rincón de la teoría) y se da prioridad al aspecto constructivo del intelecto. Y de esta manera, siendo consecuencia tanto del escotismo como del ockhamismo, ya en Suárez vemos que, "frente a la intentio obiectiva o intentio intellecta, surge otra modalidad de intentio, en la que ya no se atiende primordialmente al objeto y su modo de darse en el sujeto, sino que se atiende al acto intencionante». ${ }^{26}$

25 K. Michalski, «Le criticisme et le scepticisme». pp. 135-136.

26 S. Rábade Romeo, La estructura del conocer humano, Madrid: F. del Toro, 1969, p. 69. 
Fue en los autores tomistas, como Juan de Santo Tomás (quien aceptaba el enuntiabile o iudicabile, pero no con un sentido platónico, sino con un sentido aristotélico); donde se conservó la species con todas las características que le adjudicaba el Aquinate; pero no tenían la influencia que tuvieron los maestros nominalistas sobre los nuevos pensadores (como Hobbes y Locke, por ejemplo) ni la que tuvo Suárez sobre ellos (como Descartes y Leibniz, por ejemplo), influencias que, juntas, depararon el advenimiento de lo que conocemos como la filosofía moderna (con su interés tan centrado en el conocimiento).

Mauricio Beuchot

Apartado postal, 23-161

Xochimilco

16000 México D.F. 